\title{
The Strategic Environmental Assessment as a sustainable territorial planning procedure
}

\author{
M. Almenar-Muñoz \\ Department of Urban Planning, \\ Polytechnic University of Valencia, Spain
}

\begin{abstract}
The main purpose of this paper is to highlight the role of the Strategic Environmental Assessment (SEA) process applied to urban and territorial planning, as a paradigm of sustainable planning, in order to reconcile environmental protection with the development of cities and the territory.

The SEA is analyzed as an instrument for achieving sustainable development and, with this purpose, those existing elements in the territory that affect territorial and urban planning must be detected and must be considered in the SEA process. This includes factors, conditions and environmental risks that have to be detected in the initial phase of SEA (identification).

The right to enjoy an appropriate environment and the duty to preserve it requires the authorities to ensure the rational use of all natural resources, in order to articulate through land-use and urban planning, more sustainable cities and territories, being essential for achieving this purpose, a proper assessment of the plan.

Keywords: Strategic Environmental Assessment, urban and territorial planning, sustainable development, factors, legal conditions and environmental risks.
\end{abstract}

\section{Introduction}

This paper is set against a backdrop of increasing environmental degradation and social concern for environmental issues. A good example of this was the recent Paris Summit on climate change, as well as the large number of ongoing environmental reports, meetings and policy reviews, meaning that the environment has become one of the main current problems. 
It is a well-known fact that we are facing a huge global conflict, one that requires urgent measures which cannot be postponed. We must bear in mind that inaction on this subject has serious consequences for the environment.

In fact, until recently, environmental matters had no influence on urban or territorial planning, as they were considered to be minor issues. We could arguably say that the environment was seen - in the not too distant past - in a poetic light.

Therefore, correct environmental assessments are essential to achieve environmentally-friendly urban planning.

For this purpose, existing elements which affect the planning process must be detected. Consequently, they must be considered in the Strategic Environmental Assessment (SEA); that is, the factors, legal conditions and environmental risks that have to be identified in its initial phase [1].

European legislation - Directive 2001/42/EC of 27 June - mandates submitting the territorial and urban planning to the SEA process, forcing Spanish legislators to incorporate the aforementioned directive into their legal framework. Hence it being known as the Strategic Environmental Assessment, through the adoption of Law 9/2006 of 28 April on the assessment of the effects of certain environmental plans and programs (LEAE).

In the case of the Valencian Community, until 2014, the SEA procedure had not been included within domestic law, which was a limiting factor in the implementation of EU environmental policy. Thus, with the approval of Law $5 / 2014$ of 25 July on the territorial, urban and landscape planning of the Valencian regional government (LOTUP), the environmental assessments incorporated in the approval of planning procedures are regulated for the first time. This has definitely endowed territorial and urban planning with legal protection, bringing about a significant improvement on the previous regulatory framework.

Therefore, the SEA is approached as an instrument for achieving sustainable territorial development, with its initial phase - that of identification - acquiring significant importance.

\section{Brief reference to the regulatory framework of the Strategic Environmental Assessment}

The requirement of an environmental assessment of the activities likely to have significant impact on the environment emerged - in the international framework - at the United Nations Conference on Human Environment held in Stockholm in 1972, and later at the United Nations Conference on Environment and Development held in Rio de Janeiro in 1992. Many of the international treaties on environment and sustainable development were born from these conferences, also including community environmental law.

A good example of this are the Directives 85/337/EEC of 27 June 1985 and 97/11/EC of 3 March 1997, concerning the assessment of the environmental effects of certain public and private projects, and - internationally - the European Economic Commission Agreement on Environmental Impact 
Assessments in Transnational Contexts (Espoo, 1991) and its Protocol on Strategic Environmental Assessments (Kiev 2003).

In that sense, Thérivel and Partidário [2] revealed that "the EIA limitations which can be overcome with an SEA comprise the inability to take into account the cumulative effects of multiple and subsequent projects in a particular field or focus on strategic choices which, in the case of being undertaken, would have canceled the need for the project contemplated in the EIA".

In short, the SEA is a preventive and administrative tool consisting of a legaladministrative procedure aimed at identifying, predicting, interpreting and communicating environmental impacts in the very early stages of a plan, in the case of being enforced, as well as the prevention, correction and evaluation of these processes. All this with the purpose of making sure the plan is accepted, modified or rejected by the various competent public authorities.

\subsection{European law: Directive 2001/42/EC}

In developed societies, environmental social awareness has intensified spurred by scientific advances relating to ecosystem protection. From the 1960s onwards, widespread concern for the environment led to the emergence of legal instruments aimed at protecting the natural environment, coupled with global action promoted by various international institutions.

The origin of the environmental impact assessment (EIA) process - as the procedure stemmed from the principle of preventive action - dates back to January 1, 1970, through the peaceful adoption in the United States of The National Environmental Policy Act (NEPA) [3], establishing the environmental impact report as a condition for the approval of projects.

In the EU, after the protracted regulation of environmental assessment procedures within one single common standard for plans and projects (EIA Directive 85/337/EEC), the European Parliament and European Council approved Directive 2001/42/EC of June 27, on the assessment of the effects of certain plans and programs on the environment (SEA Directive). However, the term strategic does not appear in the title or in the text of the directive. Yet despite this, it is still colloquially called strategic because it deals with environmental assessments at a higher - more strategic - level than that of projects, as expressed by de Gatta-Sánchez et al. [4].

Thus, all the plans and programs affecting the environment, and which had not been approved before 21 July 2006, had to be subjected to strategic environmental assessments, considering the transitional 24-month period starting from the directive's maximum transposition deadline, which expired on 21 July 2004.

Nevertheless, the EU's sustainability objectives connect the SEA Directive to the general objectives of European environmental policy, as set out in art. 6 of the EC Treaty: "the demands of environmental protection must be integrated into the definition and implementation of policies and actions of the Community, in particular with a view to promoting sustainable development".

Furthermore, Gómez-Orea [5] states that the spirit of the SEA is to first integrate the environment in the formulating process of policies, plans and 
programs (PPP), and then verify their real and practical enforcement and publish the results. Integration means including environmental sensitivities, knowledge, judgment and commitment in the development process of the plan. Verification involves two aspects: verifying that efforts have been made towards environmental integration within the plan's development and evaluating the results achieved through the identification, assessment, prevention and monitoring of impacts that would occur if executed.

In effect, and according to Utrera-Caro [6], the SEA Directive was a significant breakthrough in the process of environmental integration within sectoral policies - initiated by the European Council in Cardiff (1998) - which culminated in the adoption of the European Union Sustainable Development Strategy at the European Council in Gothenburg (2001).

The environmental assessment process stands out for its unquestionable prominence in the SEA Directive, as an instrument that must support sustainable and inclusive development, subordinating its effectiveness to -first - the submission of only those actions that could have an impact on the environment and secondly, the speed with which the procedure is processed.

In conclusion, from a conceptual point of view, the SEA process established by Directive 2001/42/EC is a decisive administrative procedure with regard to planning approval, through which likely significant effects on the environment are analyzed. Theoretically, it should also expedite the processing times of plans by identifying and considering the legal conditions and environmental risks from the start of the (planning) decision process, for the purpose of achieving shorter approval periods. However, as in the case of the Valencian Community, this has not yet been achieved due to the late adoption of the SEA Directive (in 2014).

\subsection{Spanish SEA regulations}

\subsubsection{The late transposition of the SEA Directive}

The European SEA Directive regulatory mandate to submit all planning to Strategic Environmental Assessment (SEA) processes, forced Spanish legislators to incorporate the aforementioned regulation, known as Strategic Environmental Assessment, into Spanish law, through the adoption of Law 9/2006 of 28 April, on the evaluation of the effects of certain plans and programs on the environment (LEAE). This provision entered into force on April 30, 2006, the date on which also the legal system formed by the LEAE acquired mandatory status, overriding the previous environmental assessment regulatory framework. Law 9/2006 was then itself repealed by Law 21/2013 of 9 December on Environmental Assessment (LEA).

At this point, the SEA Directive set a maximum transposition deadline for the period before 21 July 2004, that is, three years after its publication in the Official Journal of the European Union, a deadline which Spain missed since the SEA regulation entered into force on 30 April, 2006.

Thus, the new strategic environmental assessment process - established after the enactment of Directive 2001/42/EC and the entry into force of the LEAE has been the subject of relevant studies by the most authoritative figures in matters related to environmental law and Spanish environmental assessment: 
Martín-Mateo [7] and Gómez-Orea [8], respectively, and also Cuyás-Palazón [9], Farinós-Dasí [10], Fernández-García [11], Sanz-Rubiales [12] and HernándezGonzález [13], among others.

That environmental planning vision of preserving and restoring the natural environment has also long been advocated by the most authoritative authors, among which we can find Bassols-Coma [14].

However, deepening on the applicability of LEAE legislation, all the plans and programs affecting the environment, and which had not been approved before 21 July 2006, had to be subjected to strategic environmental assessments.

In short, one important issue is the full implementation of the SEA on plans starting from the entry into force of the LEAE, which did not count as of July 21 2006 with the Environmental Agency's resolution, and therefore with its final approval. Yet the development plans definitely approved after July 212006 - but which had already completed the environmental assessment process prior to the entry into force of the LEAE is a different matter.

\section{The Strategic Environmental Assessment as a sustainable territorial planning procedure}

The main purpose of this paper is to highlight the role played by the environmental assessment process as a paradigm of sustainable planning, in order to reconcile environmental protection with the development of cities and territories.

It first defines the environmental assessment process - of undeniable importance during these last few years - as a key instrument in supporting sustainable and inclusive development. Nonetheless, its effectiveness is conditioned firstly by the submission of only those actions that could have an effect on the environment, and secondly by the speed with which the procedure is processed.

Thus, Spanish environmental assessment regulations must ensure - in accordance with the Spanish Constitution - the protection and preservation of the environment, for which a basic and common framework is absolutely essential, without prejudice to the powers of the Spanish Autonomous Communities to set additional protection rules. In fact, this environmental authority must be exercised in a way that guarantees the right of everyone to enjoy life and have a safe and ecologically-balanced environment, ensuring the protection of biodiversity and other areas of special environmental importance.

In this regard, as pointed out by Gómez-Orea [15], one of the basic principles in environmental policy is prevention. This is why successive European Union environmental programs have insisted that the best course of action in this field is to avert pollution and ecological damage before it is produced, rather than trying to counteract its effects afterwards.

For the effective protection of the environment, planners must identify the constraints produced by the existence of environmental values, conditions and environmental protection provisions in the developmental stage of planning (protected areas, protected wildlife, sites of community interest, cattle trails, 
wetland areas, water, waste management, Natura 2000 spaces, natural parks, protected landscapes, forestry land, etc.), as they can make any alterations or transformations of the environment unfeasible due to the fact that land may be subject to significant environmental values, in accordance with a special legal protection system.

For this purpose, with a view to correcting environmental errors committed if any - in planning processes and which can serve as learning experiences, it is unavoidable to identify all the conditions and environmental risks posed by the territory in question in order to achieve sustainable growth, as they are essential for the proper diagnosis and development of the environmental assessment process of plans. Also, it is important to take into account other conditions which are not directly linked to environmental factors, but which influence the local territorial and urban planning, as those relating to public infrastructure such as roads, airports, railways, power lines, utility channels, etc.

In effect, a detailed analysis of the factors, environmental risks and legal conditions that define regional and town planning must be carried out to guarantee planning sustainability, paying particular attention to the consideration of new planning paradigms, such as the European Territorial Strategy and the Green Infrastructure plan. Also, environmental regulations and available official maps must be studied as they may contain essential information for planners and other agents involved in territorial and urban planning.

In current urban planning, one of the problems that has the largest impact on the environment is the projected land development of plans which are not subjected to environmental assessments, due to the fact that they were approved before the entry into force of existing environmental assessment regulations. And because they were outdone by the subsequent adoption of environmental protection provisions (sites of community interest, natural resource management planning, protected wildlife species, wetland area declarations, etc.), from a comprehensive view of territorial planning (environment, landscape and urban planning) and due to the presence in the area of action of certain factors that prevent or constrain the urban transformation of land, it may be unfeasible from an environmental perspective to implement planning which is not subject to environmental assessments, as I have shown [16].

Nevertheless, once planning is subject to environmental assessments it must establish a clear and precise relationship to determine where urban development is possible and where it is not. To that end, territorial planning must be addressed hierarchically: at a national, regional and local level, from a comprehensive perspective of the territory, incorporating landscape, cultural and environmental criteria.

Consequently, environmental assessments should be seen as an essential process for protecting the environment and - in turn - as a tool for incorporating sustainability criteria in strategic decision making. All this for the purpose of ensuring the adequate prevention of specific environmental impacts that may arise, while studying effective correction or compensation mechanisms in order to make urban growth development compatible with the preservation of territorial values. 


\subsection{Study area: Valencian Community}

In the case of the Valencian Community, the entry into force of Law 9/2006 of April 28 meant a substantial change in its approach to urban issues, incorporating environmental aspects and setting sustainability as a goal in the initial stages of planning, therefore making these matters crucially important for the proper development of the decision-making process. However, this new procedure had to fall in line with the Valencian planning regulations in force at that time - Law 16/2005 of 30 December, Valencian Urban Planning Law (LUV) of the Generalitat (Valencian regional government), which caused serious flaws in the processing and documentary content of plans. Adapting to this new regulatory framework resulted in the reorganization of the environmental administration of the Valencian regional government.

Thus, a transitional Planning and Landscape Protection standard was implemented - Law 4/2004 of 30 June, (LOTPP 2004) of the Valencian regional government, valid until August 20, 2014 - while the strategic environmental assessment - required by the SEA Directive - remained incomplete. In it, specific territorial and urban planning instruments were assessed, according to the environmental assessment regulations in force at that time.

In addition, the 2004 LOTPP established a series of novel concepts in order to classify the possible effects of territorial or urban development within two categories: socio-economic and urban-territorial effects, with the aim of achieving various objectives and purposes, including the protection of the environment, natural resources and living standards, while promoting sustainable urban development within the principles defined in the Spanish Constitution and the preservation and advocacy of historical, cultural, landscape and architectural heritage.

After the 2004 LOTPP, a new urban standard entered into force by means of the aforementioned Law 16/2005 of 30 December, which repealed Law 6/1994 of 15 November, Urban Activity Regulatory Law (LRAU) of the Generalitat. At this point, it is noteworthy that the new Valencian (2005) law made no reference to the SEA Directive and, consequently, to the strategic environmental assessment procedure. Hence, it continued mentioning - in terms of territorial and urban planning instruments - the old environmental impact assessment process and the outdated documentation of environmental impact studies [17].

Meanwhile, the Valencian Regional Government had no organic or functional structure adapted to the new requirements of Law 9/2006 of 28 April, which led the Generalitat (government) to restructure its urban, territorial and environmental assessment bodies, creating in 2007 the Strategic Environmental Assessment Department, becoming the very first environmental body run by one sole person, to then - from September 2011 onwards - become a collegiate body called the Environmental Assessment Commission. As just noted, the absence of legal regulation in Valencian legislation regarding SEA processes finally culminated with the LUV reform - by means of Law 12/2010 of 21 July - of the Generalitat, which facilitated the implementation of strategic environmental assessment standards, stipulating that councils must start the strategic 
environmental assessment procedure - in accordance with Law 9/2006 of 28 April - before formulating the technical text of each general plan.

In summary, it is worth stressing that after the enactment of the SEA Directive and the corresponding Law 9/2006 of 28 April, even though Valencian legislators tried to capture the spirit of the Strategic Environmental Assessment Directive in the 2004 LOTPP by applying environmental and sustainability criteria to the approval of plans, in practice the lack of regulation has led to imbalances and flaws both in the processing and documentation of the plans subjected to the SEA.

\subsubsection{Effects caused by the late SEA regulation in the Valencian Community}

In the territorial scope, we must address Law 5/2014, of $25 \mathrm{July,} \mathrm{on} \mathrm{the}$ territorial, urban and landscape planning (LOTUP) of the Generalitat-, which was originated with the clear intention of simplifying and clarifying until then a vast Valencian regulatory framework in terms of territorial, urban and landscape planning.

Here, in order to take account of the scope of legislative reform contained in the new Valencian urban planning law, it should be noted that this law's adoption led to the repeal of 6 laws and 2 regulations, expressed in the removal of 2,000 articles, which resulted in the current 270 registered in the LOTUP.

In effect, one of the most pressing and urgent issues to be addressed by Valencian legislation was the adaptation and coordination of the planning approval procedure within the environmental assessment process, set forth in the provisions of the SEA Directive and in Law 21/2013 of 9 December. Nevertheless, it should be noted that the new environmental procedure was applied de facto by the Autonomous Regional Government, yet without having the necessary statutory regulation in the Valencian Community. This clearly generated imbalances and flaws in the enforcement of the SEA, especially for planners.

However, from a legal point of view, as revealed before [18], one of the most important issues with regard to the new Valencian urban planning law of 2014, is the ex novo regulation of a planning development and assessment mechanism where environmental, territorial, landscape, economic and cultural variables converge in the same administrative procedure. This process - known as strategic environmental and territorial assessment - is based on a unified and global planning perspective, and aims to help expedite the processing of plans and provide legal certainty to all the operators involved in the field of urban and regional planning.

Furthermore, we also find incorporated in the SEA process the last environmental assessment legislative reform, articulated in Law 21/2013 of December 9, which aptly introduces - within the Spanish legal system - a single regulatory framework for the environmental assessment process, for both plans and projects, as noted by Cuyás-Palazón [19].

In short, considering the spirit of the new Valencian urban planning legislation, this law denotes a qualitative and quantitative leap forward in 
comparison with the previous regulatory framework in responding effectively to citizens' claims, since social demands require territorial and environmental planning regulations to go hand in hand. All this must be achieved through consensual planning decisions, involving all the agents working on territorial and urban planning, and avoiding all the recent flaws and dysfunctions generated in the planning approval procedure.

In order to keep this work updated, we must also mention the current configuration of the Generalitat (July 2015), that separates the substantive body (urban planning) from the environmental body, with powers conferred upon different regional departments (consellerias), which in practice can mean timing delays when it comes to planning approval. Therefore, solutions must be found with the aim of ensuring due diligence - yet without affecting the quality - of the SEA procedure, as required by European law.

Summarizing, since the entry into force of the LOTUP on August 20, 2014, the absence in the Valencian Community of proper regulation in terms of the SEA process has been solved. It now constitutes a legal provision and the legal uncertainty and procedural dysfunctions generated during the eight years of the application of the Spanish SEA regulation have been settled. This has dramatically improved the development and processing of plans on the part of planners, although all this is being said with the usual reservations born from the implementation and adaptation of new legislation on regional and local governments, as in this case.

\subsubsection{Environmental conditions of the territory}

In the case of the Valencian Community, around 43 environmental constraints must be analyzed (27 legal factors and conditions and 16 environmental risks) projected to all the other autonomous communities - to ensure the sustainable development of the territory through proper environmental assessment planning. Below are briefly presented the ones listed in Figures 1 and 2.

Both in the integration phase, which is related to planning and the verification phase, actually, the environmental assessment submission, we should take into account a number of factors, legal conditions and environmental risks that are necessary for a plan's adequate environmental integration and its response to the great challenges posed by sustainability.

Omissions or inadvertence of these factors necessarily turn into the extension of the processes, an avoidable situation if operated since the start on a thorough reference framework. Therefore, a clear and accurate guideline must be established which determines, where the urban development is possible and where not.

The environmental feasibility of the planning involves incorporating knowledge, judgment and environmental commitment to the process of elaborating the plan. Furthermore, the identification of the effects on the environment involves the speeding-up of the expediting process of the planning, by identifying and considering the conditions and environmental risks, thus avoiding malfunctions in the approval procedure of the planning. 


\section{Conditions \& legal factors}

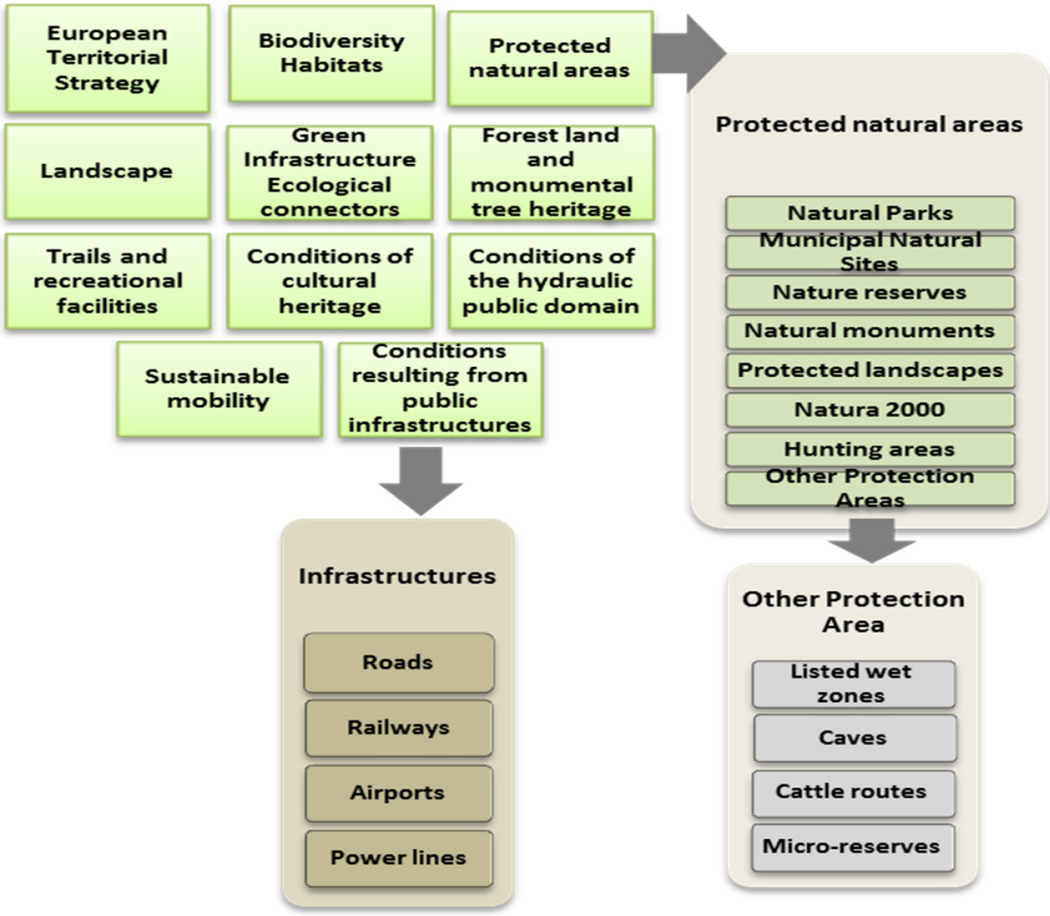

Figure 1: Conditions and legal factors.

\section{Environmental risks}
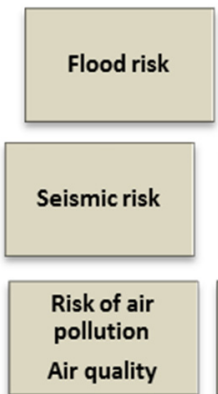

Risk of major accidents due to dangerous goods
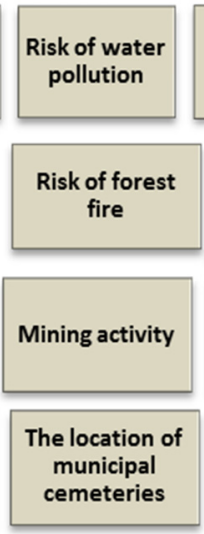

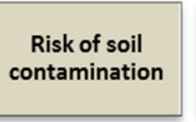

\section{Risk of erosions} and ladslides

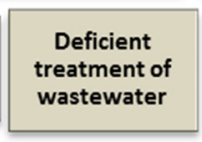

Soils with high agricultural capacity

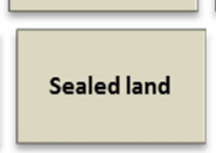

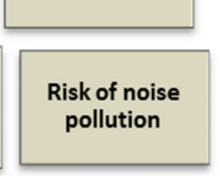

Deficient waste management

Hydrological resources

Figure 2: Environmental conditions of the territory: environmental risks. 
Ultimately, the Spanish Constitution embraced - as a guiding principle of state environmental protection - the recognition that everyone has the right to enjoy an adequate environment for their own development, as well as the duty to preserve it. This requires public authorities to ensure the rational use of all natural resources (protected areas, wildlife, water, etc.), the prevention and reduction of pollution - in order to protect and improve living standards and the defense and restoration of the environment, conciliating - in turn - economic development with the preservation of natural resources [20], with the aim of managing - through territorial and urban planning - more sustainable cities and territories. And effective environmental assessment planning is essential for achieving this objective.

In conclusion, the environmental competence of public authorities must be exercised in a way that guarantees the right of all persons to enjoy a safe environment, with the best course of action, avoid, prior to production, pollution or ecological damage, rather than subsequently trying to counteract their effects.

\section{References}

[1] Almenar-Muñoz, M., The Strategic Environmental Assessment as a sustainable territorial planning procedure, Spoken communication, Conference: Environmental rights for a green economy, A Coruña (Spain), November, 2015.

[2] Thérivel, R., Partidário, M.R., The Practice of Strategic Environmental Assessment, Earthscan Publications, London, p. 5 and seq., 1996.

[3] de la Maza, C.L., Management and preservation of forest resources, Ed. Universitaria, Santiago (Chile), 2007.

[4] Fernández de Gatta-Sánchez, D. et al., Environmental Impact Assessment and Strategic Assessment, Tirant Lo Blanch, Valencia, p. 22, 2014.

[5] Gómez-Orea, D., Strategic Environmental Assessment, Mundi-Prensa, Madrid, p. 52, 2014.

[6] Utrera-Caro, S.F., stating that the European Commission incorporates the SEA concept expressed by Sadler, B. and Verheem, R., The expansion of environmental impact assessments to plan or program policies. Ministry of Housing, Urban Planning and Environment Protection, The Hague (Netherlands), 1996.

[7] Martín-Mateo, R., Environmental Law Treaty, Vol. IV, Trivium, Madrid, p. 7, 2014.

[8] Gómez-Orea, D., Strategic Environmental Assessment, Mundi-Prensa, Madrid, p. 5 and seq., 2014.

[9] Cuyás-Palazón, Mª. M., Environmental urban planning and strategic environmental assessment, Atelier Libros Jurídicos, Barcelona, p. 3 and seq., 2007.

[10] Farinós-Dasí, J., From strategic environmental assessment to territorial impact assessment: Reflections on the assessment task, University of Valencia Publishing Services, p. 20, 2011. 
[11] Fernández-García, J.F. et al., The environmental assessment of urban and territorial planning, Wolters Kluwer, Madrid, p. 10 and seq., 2006.

[12] Sanz-Rubiales, I., Notes on the legal system covering the strategic assessment of plans, in Law 9/2006, in RDA $\mathrm{n}^{\circ}$. 12, 2007, pp. 47-73, 2007.

[13] Hernández-González, F.L., The strategic environmental assessment of territorial and urban planning. Regional legislation analysis, in Urban Planning Law in the XXI century (commemorative volume for Prof. M. Bassols Coma) Vol. II, Bosch, Barcelona, p. 261 and seq., 2008.

[14] Bassols-Coma, M., Urban Planning and The Environment, in Law and The Environment, CEOTMA, Monograph Series núm.4, RodríguezRamos (coord.), Madrid, p. 24, 1981.

[15] Gómez-Orea, D. et al., The origins of the strategic environmental assessment (SEA) and its link to the territorial impact assessment, in Farinos-Dasi, J., From the strategic environmental assessment to the territorial impact assessment: reflections on the assessment task, University of Valencia Publishing Services, p. 172, 2011.

[16] Almenar-Muñoz, M., The processing of plans and programs, with a special mention for environmental assessments, in The new urban planning legal system of the Valencian Community, (collective work), Tirant Lo Blanch, Valencia, p. 191, 2015.

[17] Introduction to Environmental Impact Studies, Official Association of Agronomists of Levante, Valencia, 1989.

[18] Almenar-Muñoz, M., La tramitación del planeamiento, con especial referencia al procedimiento de evaluación ambiental, en Nuevo régimen jurídico urbanístico de la Comunidad Valenciana, (collective work), Tirant Lo Blanch, Valencia, p. 205, 2016.

[19] Cuyás-Palazón, M ${ }^{\mathrm{a}}$. M., The environmental assessment whirlwind. Some of the novelties in Law 21/2013, of 9 December, Aranzadi Journal of Urban Planning and Construction, no. 31, pp. 3-4, 2014.

[20] Kulsum A., Sánchez-Triana E., Strategic Environmental Assessment for Policies: An Instrument for Good Governance, International Bank for Reconstruction and Development, World Bank, Washington, DC, 2008. 